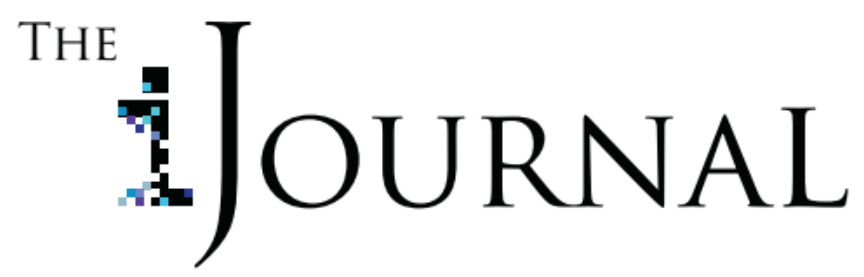

\title{
Dismantling White Supremacy in GLAMs and GLAM Education [Galleries, Libraries, Archives, Museums]
}

The Diversity Working Group (Renee Saucier, Stefanie Martin, Moska Rokay, and Tomoko Shida)

\section{Abstract}

For the 2019 Information and Museum Studies Conference, a group of five Master's students offered a workshop titled Dismantling White Supremacy in GLAMs and GLAM Education [Galleries, Libraries, Archives, Museums]. This workshop was based on activities developed by the Archivists Against collective. This workshop was not a one-off event, but rather the first action of the Diversity Working Group, a student-led entity at the Faculty of Information.

\section{Keywords}

Archives, Libraries, Museums, Archival Education, White Supremacy, Professional Education, Equity, Race, Diversity 
Diversity Working Group / Dismantling White Supremacy in GLAMs and GLAM Education

\section{Introduction}

For the 2019 Information and Museum Studies Conference, a group of five Master's students offered a workshop titled Dismantling White Supremacy in GLAMs and GLAM Education [Galleries, Libraries, Archives, Museums]. At the time, four of the facilitators were Master of Information students concentrating in Archives and Records Management, and one was pursuing a Master of Museum Studies. Broadly speaking, we were brought together and motivated by a dissatisfaction with the absence of a critical race perspective in the curriculum and a seemingly general lack of awareness and concern for racial equity at the Faculty of Information. Combined with and compounded by a student body and professional field that is grossly disproportionately white, this absence results in a perpetuation of the status quo and negatively impacts racialized individuals navigating graduate school and entering the profession. This issue urgently needed to be identified and addressed, and we sensed that others in the faculty shared this conviction.

Earlier in the semester, the student chapter of the Association of Canadian Archivists had organized a panel on "Deconstructing 'Diversity' in the Archival Profession". This panel had been well-attended and well-received, and, in some ways, could be seen as the opening notes of a larger conversation. In developing our workshop, we drew on the resources and work of critical archival studies scholars and the Archivists Against History Repeating Itself collective. ${ }^{1}$ The Archivists Against collective is doing work and developing resources "in order to acknowledge, address, and repair the harms done by white supremacy, colonialism, patriarchy, heteronormativity, ableism, and capitalism ... and their various intersections in and through records and archives" (Archivists Against).

Specifically, we modeled our workshop on Michelle Caswell's "Dismantling White Supremacy in Archives" group exercise. We broadened the focus to accommodate the concentrations/academic areas of the Faculty, which include Library and Information Sciences, Information Systems Design, User Experience Design, Critical Information Policy Studies, and Culture \& Technology in addition to Archives \& Records Management and Museum Studies.

\section{A Diagram of the Workshop}

\section{Introductions}

The workshop began with introductions by the facilitators and a brief icebreaker, which had the attendees introduce themselves to each other and share what brought them to the workshop. When wrapping up the introductions, we presented some guidelines for creating an inclusive space for discussion. Adapted from discussion guidelines developed by the University of Michigan's Center for 1 Thanks should also be given to Joy Rowe (Twitter: @resistancereces) who offered encouragement to students and new professionals and in particular encouraged a workshop drawing on the resources of Archivists Against. 
Diversity Working Group / Dismantling White Supremacy in GLAMs and GLAM Education

Research on Learning and Teaching, and used in the Archival Appraisal course taught by Karen Suurtamm (winner of the 2019 MISC Outstanding Instructor Award), they are presented below:

"Be mindful of including all voices in the discussion: If you have a lot to say, hold back a bit; if you are hesitant, look for opportunities to speak up."

"Be mindful of your positionality / privilege."

"Be kind: recognize that we are all still learning, that we come with different experiences and levels of awareness" (University of Michigan, 2018).

We felt that these guidelines were pertinent for several reasons, particularly given that our workshop participants were a mixture of students, alumni, and faculty.

\section{Definitions}

Before moving into the main activities, we set out to clarify three key concepts: white supremacy, white privilege, and white fragility. Workshop participants took a few minutes to write down definitions of these terms for themselves, for their eyes only. Then, we offered definitions and invited participants to compare their own articulations to these. The aim of this activity was, first, to ensure that everyone in the room was working roughly with the same concepts and, second, to invite participants to take stock of their own understanding of and comfort in using/employing these terms.

In working with definitions of white supremacy, we hoped to emphasize its systemic, structural nature, and referred to a graphic representing 'overt white supremacy (socially unacceptable)' vs 'covert white supremacy (socially acceptable)' [Figure 1]. Notably, the examples of 'covert white supremacy' included several that we had observed or experienced throughout higher education (Eurocentric curriculum, tokenism, "assuming that good intentions are enough," white savior complex). We hoped that these examples would prompt participants to reflect on their own experiences to identify and examine manifestations of white supremacy. 
Diversity Working Group / Dismantling White Supremacy in GLAMs and GLAM Education

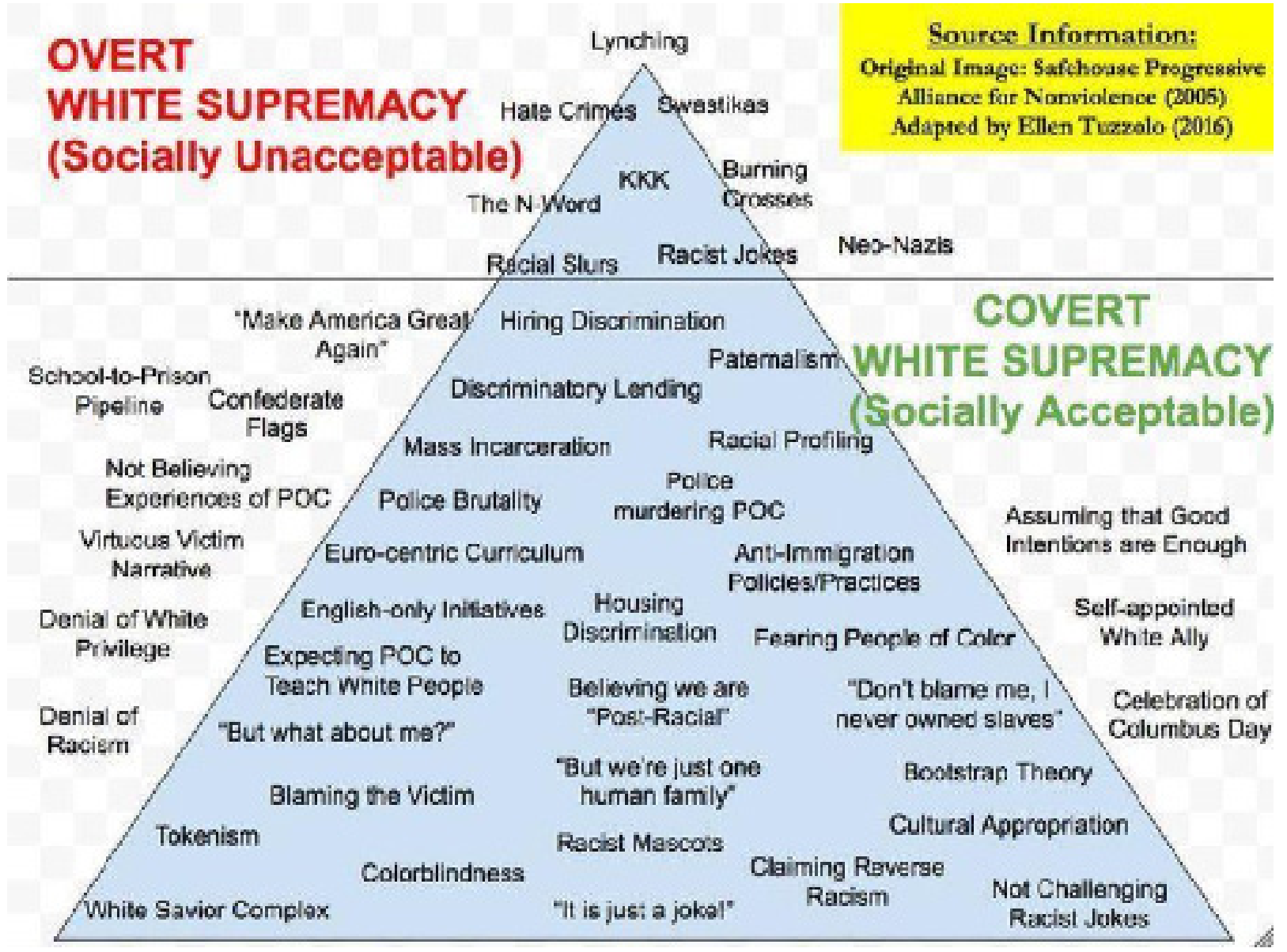

Figure 1. Various manifestations of white supremacy. Reproduced by Unitarian Universalist College of Social Justice, by Safehouse Progressive Alliance for Nonviolence, 2005, retrieved from https://uucsj. org/study-guide/legacies-of-systemic-injustice/white-supremacy/

Drawing on the words of Frances Lee Ansley, we offered a definition of white supremacy as not just "the self-conscious racism of white supremacist hate groups" but

a political, economic and cultural system in which whites overwhelmingly control power and material resources, conscious and unconscious ideas of white superiority and entitlement are widespread, and relations of white dominance and non-white subordination are daily reenacted across a broad array of institutions and social settings. (Frances Lee Ansley, as quoted in Newkirk 2017)

In discussing white privilege, we highlighted several of its facets, including the fact that it is often enjoyed by white people unconsciously. The most visible manifestation of this privilege being that, in comparison to people of colour in the same situation, white people have more access to both power and resources. We described white fragility as "... the disbelieving defensiveness that white people exhibit when their ideas about race and racism are challenged-and particularly when they feel 
Diversity Working Group / Dismantling White Supremacy in GLAMs and GLAM Education implicated in white supremacy" (Robin DiAngelo, paraphrased Collins, 2018).

\section{Yes/No/Maybe}

The intention for our first activity -- "Yes/No/Maybe" -- was for participants to identify their relationships to and understanding of white privilege, individually and collectively. We posted two large signs at opposite ends of the room, one reading 'YES' and the other ' $N O$ '. As a facilitator read out five examples of the presence or absence of white privilege, participants and workshop facilitators physically moved between the two poles. The five chosen examples were as follows:

1. I can easily find academic courses and institutions which give attention only to people of my race.

2. I have been asked to speak for all the people of my racial group at work or in class.

3. I can take a job with an affirmative action/employment equity employer without having my co-workers on the job suspect that I got it because of my race.

4. If I declared there is or isn't a racial issue at hand at my place of work or study, I would be taken seriously, and action would be taken.

5. I can walk into an archive, library or museum and find materials representing my culture/community/people that is not centred around marginalization or stereotypes.

As a group, we (the facilitators) had selected and adapted these privileges from Peggy Mclntosh's (1990) "White Privilege: Unpacking the Invisible Knapsack." While it would have been ideal to expand this activity with additional examples of privileges, it was limited due to time constraints. The original workshop materials suggested having the group read the entire list of privileges aloud, but we felt that an abbreviated and embodied engagement would be more impactful.

\section{Facts, Figures and Examples}

Following this activity, we offered a brief presentation of facts and figures on professional diversity within libraries, archives and museums. Our intention here was to provide statistical data to contextualize individual experiences. According to Statistics Canada (2016), while visible minorities make up $20.8 \%$ of the total Canadian workforce, only $11 \%$ of librarians, $7 \%$ of archivists, and $4-6 \%$ of museum professionals identify as visible minorities. These figures can be compared to the underrepresentation of visible minorities among police officers (8.4\%), journalists (11.78\%) and lawyers $(13.35 \%)$.

To further illustrate the relationship between white privilege and white fragility, we played a short video clip from a debate over Canada Reads (a battle of the books, or Canada's version of the TV show Survivor). In its seventeen-year history, a book by an Indigenous woman has never been selected. Their works have been voted off for being "too dark" or "not accessible to white males" (CBC Radio 2018). In the video clip, a white television personality, Jeanne Beker, exemplifies white fragility 
Diversity Working Group / Dismantling White Supremacy in GLAMs and GLAM Education

when she accuses Canada Reads panelist Jully Black of "attacking" her. Black responds:

We are silenced, while forced to carry the emotional burdens of white fragility and white privilege; and forced to silence ourselves before white women, who weaponize their fragility by defaulting to victim mode when faced with a black woman carrying knowledge and understanding. (Black, 2018)

The video clip was well-received by workshop participants, and seemed to be effective in conveying the interconnections of white privilege and white fragility in Canada's cultural/heritage sector.

\section{Post-It Activity}

We then segued into the main activity of the workshop, modeled on the one developed by Michelle Caswell and posted to the Archivists Against resource page. Dividing participants into groups according to their academic concentration, and supplying them with poster paper and markers, we asked them to brainstorm and list how white privilege exists in their concentration/professional field and the subsequent action to dismantle it. As an example, we presented the "Description" panel of the identifying \& Dismantling White Supremacy in Archives poster [Figure 2].

\section{Identifying \& Dismantling White Supremacy in Archives}

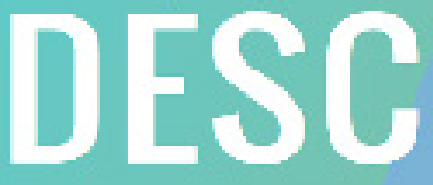

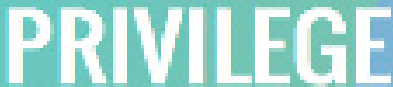

When I look for materials from my commuaity in ardhives, they will be described in the finding aid and catelog records using language we vise to deacribe. ourselves.

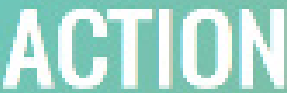
- Train all archivists to have cultaral humility and describe materials usting unti-oppressive langatspe. - Educate yoursalf continually and coastantly: - Hire more architvists of colar to deacribe materlals. - Bagnge commanlities to ask how they wish to describe themselves. Compensate them tor their tabor
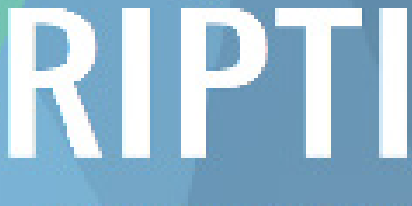

PRIVILEGE

When I look at descriptions of archival materials, I am not always bombarded by/reminded of my otherness.

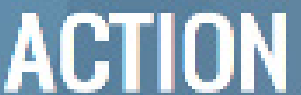

- Hire mare archivists of colar to dexcribe materislx.

- Update finding aids that use ourddated whitesinpremactist

langeage. Keep a note of your changes so thai users can exsmine the bistery of the finding ald as en artifact.

- Engage communitice to ask how they wish to descrlbe themselves. Compersate them for thetr hbot

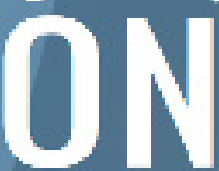

PRIVILEGE

Materials ane described

using my native language.

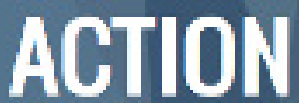

- Hire multilingeal people as archivists and translalors and translate finding oids into apreopriate langrages. - Encourage, value, and gire credit for language courses in MUS programs and ss cuntinuing sducation. 
Diversity Working Group / Dismantling White Supremacy in GLAMs and GLAM Education

Figure 2. Portion of poster on identifying and dismantling white supremacy in archives. Content produced in Michelle Caswell's Archives, Records, and Memory class, Fall 2016, UCLA, and poster design by Gracen Brilmeyer.

We had prepared various documents to inspire and support groups that were struggling (iSchool Syllabi Topics, the iSchool's TRC commitment, the entire ArchivistsAgainst wall poster, and a list of white privileges in GLAM), but these proved not to be needed. We then held a gallery viewing, inviting participants to circulate and observe each others' work. This was followed by a closing debrief and discussion, where we shared ideas that stood out and similarities between the groups.

Notably, several groups recommended similar concrete, specific classroom actions. The LIS group suggested that class readings "includ[e] recent articles by BIPOC (Black, Indigenous, and People of Colour) librarian-scholars of all backgrounds," which they termed the "new canon" of LIS scholarship. This group highlighted that the profession needed not just recruit BIPOC librarians, archivists, and information professionals, but to retain them. In support of this, they recommended "meaningful training \& implementation of EDI [Equality, Diversity and Inclusion], but NOT as a 101." Similarly, the group of students studying Critical Information Policy Studies and Culture \& Technology advised "Assign readings from diverse perspectives, be aware of racism \& white supremacy in readings (whether overt or not)" as well as "Training for faculty, instructors, TAs, students on making classroom anti-racist space, confronting racism, etc."

\section{TRC Commitments}

After the debrief discussion, we took a few moments to display and reflect on the Faculty of Information's Commitment to the Findings And Call for Action of the Truth and Reconciliation Commission. In this document, the Faculty committed to six concrete action items, including "the participation of all iSchool members in cultural awareness training." This Commitment was approved over three years ago, but most of it still has not been realized. We invoked the Faculty's TRC Commitments in order to call attention to their neglect, which we speculate is symptomatic of a larger reluctance to engage with issues of racial (in)equity within the iSchool and the profession at large.

\section{After}

We approached this workshop not just as a one-off event, but as an opening into a larger conversation and ongoing work within the Faculty of Information. At the close of the workshop we announced our intention to establish a collective that would continue working to dismantle white supremacy within the field. We intend for this collective to become a recognizable entity and, with peer support, to maintain momentum among community members who are already thinking about these issues. The objectives of "The Diversity Working Group" (our working name at the moment) are threefold: 
Diversity Working Group / Dismantling White Supremacy in GLAMs and GLAM Education

1. To effect changes to the curriculum, specifically, to introduce critical race perspectives to the ARM, LIS, MMst curricula to redress the curriculum's Eurocentric biases, in order to foster a cohort that is aware of and ready to identify racial inequity within their respective professions.

2. To create a safe space for BIPOC and allies to share experiences and learn from each other, to provide the necessary support network and will to confront white supremacy.

3. For the iSchool to uphold its TRC Commitments [The iSchool's failure to uphold its 2016 TRC commitments (as outlined in the "Faculty of Information's Commitment to the Findings And Call for Action of the Truth and Reconciliation Commission") is symptomatic of a larger reluctance to engage with issues of racial (in)equity within the iSchool and profession at large].

In July 2019, the Diversity Working Group became an official working group of the Master of Information Student Council. For the upcoming 2019-2020 school year, we are pursuing the following four main initiatives:

1. BIPOC student gatherings (twice a semester, with food).

2. Participation in a campus-wide Professional Faculties Reading Group, a JHI-supported initiative started by Anver Emon (Professor of Law \& History/ Director of Institute of Islamic Studies at UofT) that supports students (and others) in thinking critically about race, religion, ethnicity, and identity issues in curricula and professions, focusing on the professional faculties at the UofT.

3. Coordinating a campus visit from scholar-activists working toward shared goals.

4. Lobbying for the establishment of a scholarship and/or internship specifically earmarked for BIPOC students.

\section{Contact}

The Diversity Working Group welcomes/invites correspondence from interested members of the iSchool community and the profession at large! The Diversity Working Group can be reached at thediversityworkinggroup@gmail.com.

\section{Bibliography [of materials used directly in workshop]}

Archivists Against History Repeating Itself http://www.archivistsagainst.org/

Black, J. (2018, April 4). Take it to the altar: Why I spoke up at Canada Reads. Retrieved from https:// byblacks.com/main-menu-mobile/opinion-mobile/item/1858-take-it-to-the-altar-why-i-spokeup-at-canada-reads

Caswell, M. (2017). Dismantling White Supremacy in Archives. Retrieved from http://www.archi vistsagainst.org/wp-content/uploads/2018/08/DismantlingWSExcercise-1.pdf 
Diversity Working Group / Dismantling White Supremacy in GLAMs and GLAM Education

Caswell, M \& Brilmyer, G. (2017). Teaching to dismantle white Supremacy in the archives classroom. Library Quarterly 87(3), 222-235.

CBC Radio. (2018, November 23). 'That should win': Indigenous authors share experiences as final ists on Canada Reads. Retrieved from https://www.cbc.ca/radio/unreserved/books-censor ship-and-what-happens-when-indigenous-lit-goes-mainstream-1.4882446/that-should-win-in digenous-authors-share-experiences-as-finalists-on-canada-reads- 1.4882896

Collins, C. (2018). What is white privilege, really? Teaching Tolerance 60 (Fall). Retrieved from https:// www.tolerance.org/magazine/fall-2018/what-is-white-privilege-really

Ghaddar, J., Sheffield, R., Wong, D, \& MacDonald, L. (2019, February 13). Panel Discussion: Decon structing 'diversity' in the archival profession. Panel discussion at the University of To ronto Faculty of Information. Retrieved from https://ischool.utoronto.ca/news/ deconstructing-diversity-in-the-archival-profession/

Gillborn, David. (2006). Rethinking White Supremacy. Ethnicities 6(3), 2006, 318-340.

"Identifying \& Dismantling White Supremacy in Archives: An Incomplete List of White Privileges in Archives and Action Items for Dismantling Them." (2016). Content produced in Michelle Caswell's Archives, Records, and Memory class, Fall 2016, UCLA. Poster design by Gra cen Brilmeyer Retrieved from http://gracenbrilmyer.com/dismantling_whiteSu premacy_archives3.pdf

McIntosh, P. (1990). Unpacking the knapsack of white privilege. Independent School 49 (2), 31-36. Retrieved from http://psac-ncr.com/white-privilege-unpacking-invisible-knapsack

Newkirk, Vann R. (2017, October 6). The Language of White Supremacy. The Atlantic https://www. theatlantic.com/politics/archive/2017/10/the-language-of-white-supremacy/542148/

Safehouse Progressive Alliance for Nonviolence, "White Supremacy." (Reproduced by Unitarian Uni versalist College of Social Justice, 2005) https://web.archive.org/web/20190804153537/ https://uucsj.org/study-guide/legacies-of-systemic-injustice/white-supremacy/

Statistics Canada. (2016). Occupation-National Occupational Classification (NOC), Employment Income Statistics, Highest Certificate, Diploma or Degree, Visible Minority, Work Activity During the Reference Year. 2016 Census of Population, Statistics Canada Catalogue no. 98400-X2016356. 
Diversity Working Group / Dismantling White Supremacy in GLAMs and GLAM Education

University of Michigan Center for Research on Learning and Teaching. (2018, October 14).

Examples of discussion guidelines. Retrieved from https://web.archive.org/ web/20181014014015/http://www.crlt.umich.edu/examples-discussion-guidelines.

University of Toronto Faculty Council. (2016, February 4). Faculty of Information's Commitment to the Findings and Call for Action of the Truth and Reconciliation Commission. Retrieved from https://ischool.utoronto.ca/wp-content/uploads/2017/11/iSchools-TRC-Commitment.pdf 